\title{
Carrying Capacity of Semi-Rigid Joint of Timber-Concrete Beams
}

\author{
Petr Agel ${ }^{1, a}$, Kristýna Klajmonová ${ }^{2, b *}$, Antonín Lokaj ${ }^{3, c}$, Roman Fojtík $^{4, d}$ \\ ${ }^{1,2,3,4}$ Department of Building Structures, Faculty of Civil Engineering, VŠB-Technical University of \\ Ostrava, Ludvíka Podéště 1875/17, 708 33, Ostrava, Czech Republic, Europe
}

apetr.agel@vsb.cz, ${ }^{b}$ kristyna.klajmonova@vsb.cz, ${ }^{c}$ antonin.lokaj@vsb.cz; ${ }^{d}$ roman.fojtik@vsb.cz

Keywords: joint, timber, concrete, composite, steel plate.

\begin{abstract}
The aim of this article is a presentation of the results of laboratory tests and numerical and analytical modeling of timber-concrete composite beams with semi-rigid joints made of steel plates and convex nails. Due to good quality of used materials, composite timber-concrete constructions are considered a suitable solution for new buildings and reconstructions of ceiling constructions of residential and civil buildings. There are numerous ways to create a connection (joint) between timber beam and concrete slab. The methods of coupling are more and more sophisticated which carries considerable demands on control of implementation and technological practice.
\end{abstract}

\section{Introduction}

Timber ceiling constructions were used profusely for individual housing and civil constructions in the past. These constructions were favored especially for their light weight, immediate static action and low technological demands on implementation. In time, prefabricated concrete panels became more preferable in constructions due to higher carrying capacity and better acoustic properties.

Nowadays, there is increasing demand on economical, ecological and development sustainability aspects of the construction. Timber and wood-based materials are of organic origin and meet all requirements stated above. Wood and concrete composites, which are connected by good qualities of both materials, appear to be very appropriate for modern and ecological construction [1]. These composite ceiling constructions are largely made by timber ingots (beams), which interact with reinforced concrete slab. That way the composite T-section is created, which with good design can use concrete in compressed part and timber in tensile and bending part. Interaction of both parts of section and proper distribution of tension on section height must be secured by connection means.

It is possible to use large variety of connective means [2] for joining timber beam and reinforced concrete slab today. It can vary from simple methods of joining by steel nails or pikes, all the way to glued batten or trestles [3]. Steel joint does not always have to be used as a coupling mean. In literature there are also described different types of carpenter connecting method of upper surface of timber beam working in a way, which it creates natural trestles or notches working as a coupling means. By using sophisticated methods of joining, e.g. glued steel batten, it is possible to achieve almost rigid connection. On the other hand, coupling elements based on dowel type connection methods, such as joining by nails, screws, or steel perforated plates and convex nails, creates a semi-rigid joint [4].

The aim of this paper is to verify possibilities and functionality of connection of timber-concrete ceiling by thin perforated steel plates, which are nailed to the timber element by convex nails and embedded in reinforced concrete slabs. In many cases simple connection of concrete and timber was more effective than more technologically advanced methods [5], [6]. Tests of timber-concrete composite beams, which were designed to meet aims stated in this article, are described below.

\section{Model, Tests and Methods}

Numerical Model. Before carrying out tests on real samples, it was necessary to know approximate values of strain, at which samples get damaged. It was possible to get these values by creating numerical FEM model. Shell-beam model was created in software SCIA Engineer for these 
simulations. This model was chosen for its easy manipulation with location and number of coupling means.

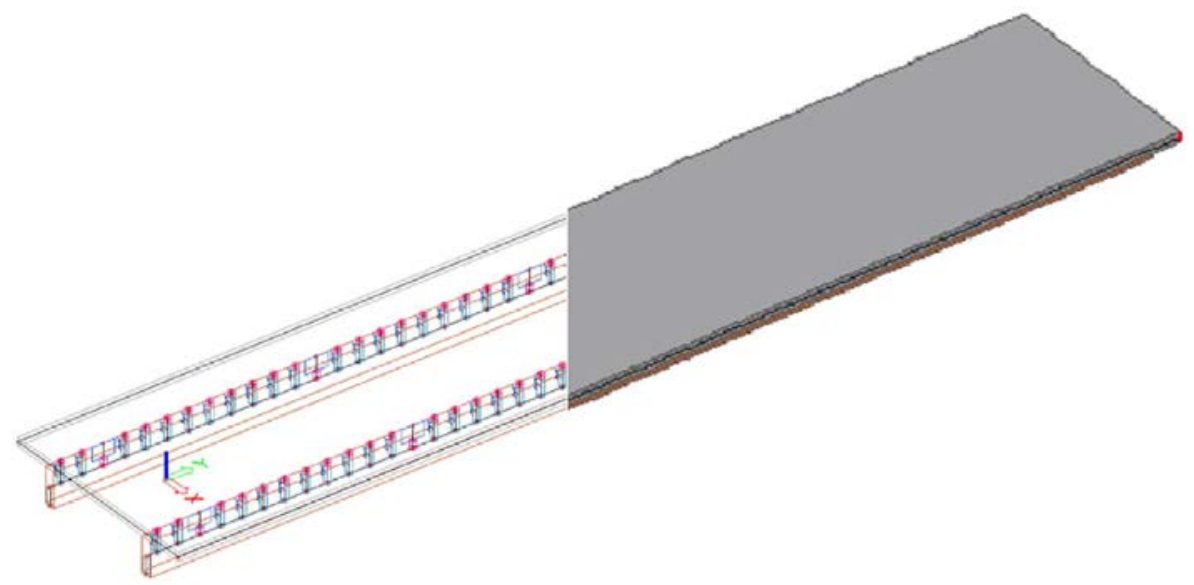

Fig. 1: Shell-beam model of timber-concrete element made in software SCIA Engineer

Numerical model (Fig.1) is made of two parallel beams with axial distance of $900 \mathrm{~mm}$ that are hinged on both ends (like in four-point bending test).Beams were connected to $60 \mathrm{~mm}$ thick plate with two types of short rods. First type had the real measures, deformational parameters and boundary conditions typical for used coupling means (steel plate and convex nails). Second type simulates friction between timber beams and concrete plate, which occurs in real situation.

Model was loaded similarly to the four-point bending test, it means by four vertical forces $\mathrm{F}_{1}$ located in a thirds of span (Fig. 2). Value of the forces was gradually increased until the maximum normal stress in timber part of the cross section reached the value of $24 M P a$, which was considered as the limit of carrying capacity of cross section.

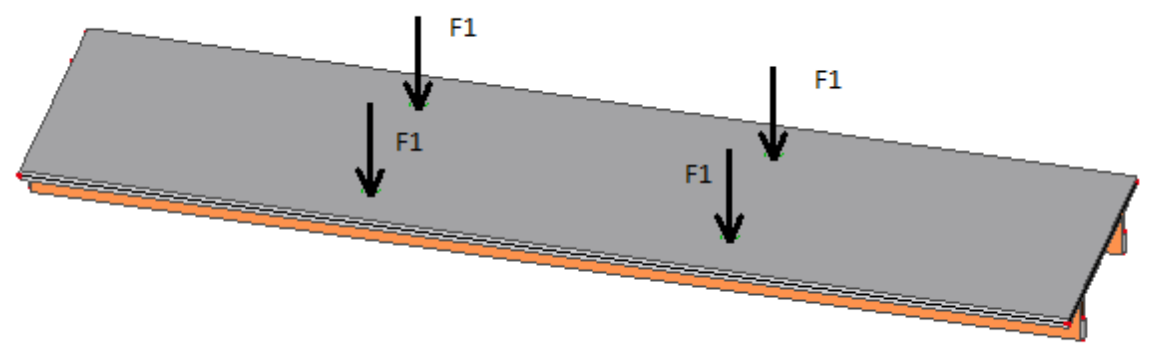

Fig. 2: Placement of loads in model situation

Laboratory Test Samples. Four laboratory samples in a TT-shape (Fig. 3) were made for experimental verification of carrying capacity of joint. These test panels were $6 \mathrm{~m}$ long and $1.5 \mathrm{~m}$ wide. Concrete C20/25 with KARI reinforcement class 10505 (wire $\varnothing 5 \mathrm{~mm}$, raster 100/100 mm) was used for production of samples. Timber beams were made from planed spruce timber type KVH of strength class C24 with moisture content of $12 \%$ and cross section $80 \times 240 \mathrm{~mm}$. Connection was made by steel plates (BOVA) size $160 \times 160 \times 2.0 \mathrm{~mm}$ nailed to beams on both sides by convex nails diameter of $4 \mathrm{~mm}$ and length of $40 \mathrm{~mm}$. The number of steel plates was selected to 16 pieces per beam for samples A and D and 32 pieces per beam for samples B and C.

Laboratory Measurements. After 28 days of solidifying the samples were subjected to carrying capacity four-point bending test in TZÚS Ostrava (Fig. 3).

These values were measured and recorded during test:

- carrying capacity force $(\mathrm{kN})$

- deflection in mid span (mm)

- deformation of wood perpendicular to grains in supports (m)

- stress in lower grains of timber cross section (MPa) 
- $\quad$ stress on lower face of timber-concrete panel (MPa)

- $\quad$ stress on upper face of timber-concrete panel (MPa)

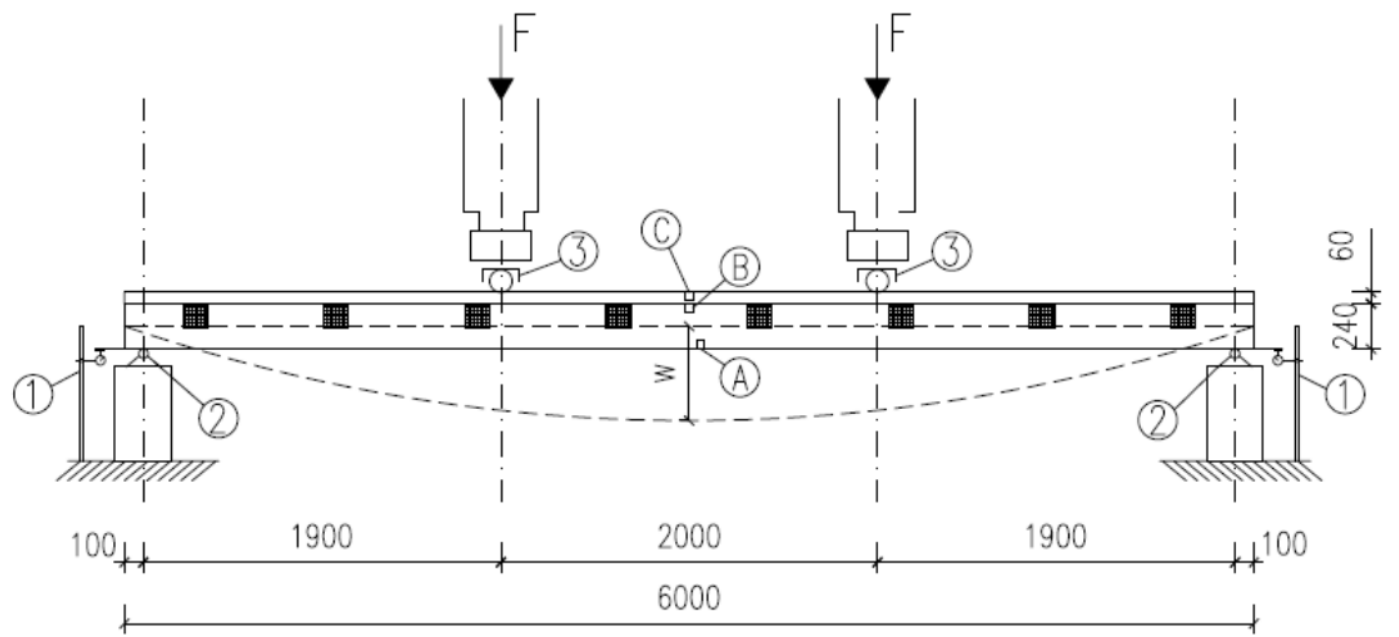
(1) MEASUREMENT OF DEFORMATION ACROSS THE GRAIN
(A) TENSION SENZOR AT THE BOTTOM OF THE BEAM
(2) STEEL PIPE SUPPORT FIXED WITH PLASTER
(B) TENSION SENZOR AT THE BOTTOM OF THE SLAB
(3) POINT OF FORCE ACTION
(C) TENSION SENZOR ON THE TOP OF THE SLAB

Fig. 3: Scheme of bending test of timber-concrete TT panels

\section{Test Results and Comparison}

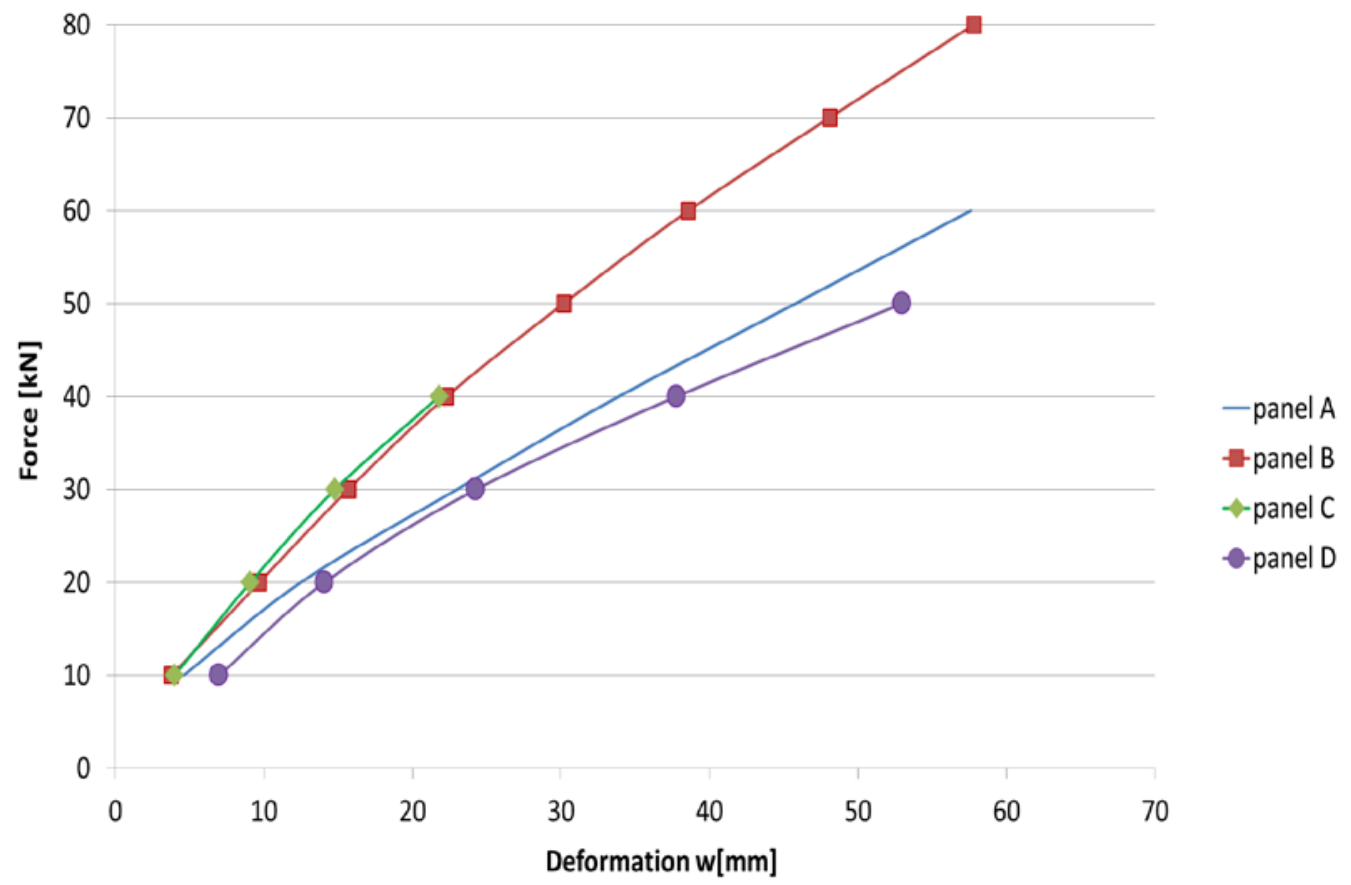

Fig. 4: Scheme of bending test of timber-concrete composite TT panels

Course of the tests were recorded in diagram for relation of deformation on total force $\left(F=4 \times F_{1}\right)$ (Fig. 4). Damage occurred in all samples in drawn grains of timber beams (Fig. 5). After the beams collapsed, concrete slab was disrupted in the place burdened by tension. The joints were not damaged. Analytical calculation and FEM model simulation shows the same results. 


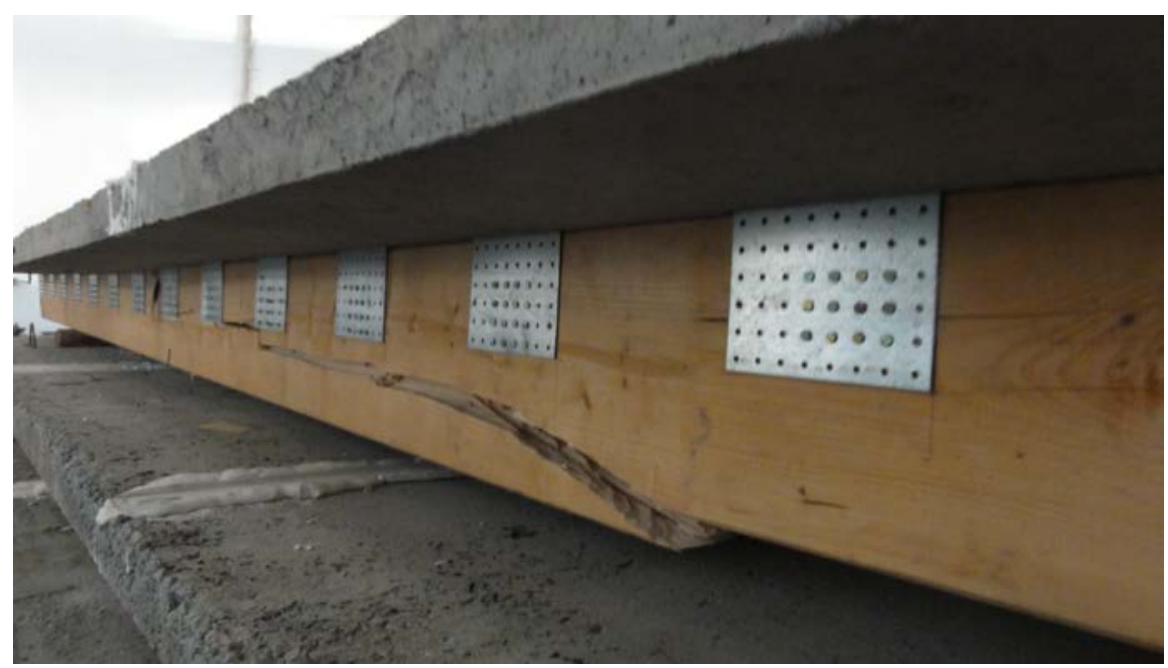

Fig. 5: Damage of timber beam along grains

Additional analysis of the construction was made on timber samples using the same static scheme as the four-point bending test of timber-concrete composite panels. Also concrete samples and nails were tested separately. Used calculation follows the procedure described in [7], [8] and [9] with use with use of the effective stiffness on the cross section. These additional tests and calculations are described in detail in [10].

The maximum possible load force on timber-concrete panels A, D and B, C were obtained from: four-point bending test performed on panels, analytical calculation during four-point bending test on and four-point bending test in FEM model. Comparison of the maximum load force $(\mathrm{F}=4 \times \mathrm{F} 1)$ is shown in Tab. 1.

Tab.1: Carrying capacity of timber-concrete panels

\begin{tabular}{|l|c|c|c|c|}
\hline Sample & $\begin{array}{c}\text { Steel plates per beam } \\
\text { (pcs.) }\end{array}$ & $\mathbf{F}_{\text {tot,test }}(\mathbf{k N})$ & $\mathbf{F}_{\text {tot,an }}(\mathbf{k N}$ & $\begin{array}{c}\mathbf{F}_{\text {tot,FEM }}(\mathbf{k N} \\
\text { ) }\end{array}$ \\
\hline A,D & 16 & 72.6 & 72.6 & 60.8 \\
\hline B,C & 32 & 76.4 & 76.4 & 82.4 \\
\hline
\end{tabular}

$F_{\text {tot,test }}$ - total load force during four-point bending test (higher value)

$F_{\text {tot,an }} \quad$ - total load force in analytical calculation during four-point bending test

$F_{\text {tot,FEM }}$ - total load force during four-point bending test in FEM model

\section{Conclusion}

Comparison of results from analytical calculation indicates, that doubling the number of connection means, according to standard method, the total cross section carrying capacity does not significantly increase (about $5.2 \%$ ) On the other hand, the difference between carrying capacity of types A, D and $\mathrm{B}, \mathrm{C}$ within the FEM model is relatively large (35\%). After comparison of test results from Fig. 4 and results showed on tab. 1 . Results of four-point bending test on panel B indicate that FEM model simulation is closer to the reality. This hypothesis is not possible to confirm by test on the panel C. Its carrying capacity was much lower than expected. It was probably caused by poor quality of finger joint in timber beam, where the damage occurred. However, the number of TT panel samples is small, further research will focus on the analysis of numerical models. 


\section{Acknowledgement}

This outcome has been achieved with funds of Conceptual development of science, research and innovation assigned to VŠB - Technical University of Ostrava by Ministry of Education Youth and Sports of the Czech Republic

\section{References}

[1] B.H. Ahmadi, Behavior of composite timber-concrete floors. Journal of structural engineering 109 (1993): 3111-3130.

[2] Steinberg, R. Sele, T. Faust, Connectors for timber-lightweight concrete composite structures. Journal of structural engineering 129(11)(2003): 1538-1545.

[3] A. Mandaris, Evaluation of timber concrete composite floors, Lund University, 2010.

[4] P. Agel, A. Lokaj, Laboratory tests of load bearing capacity of mechanical joint of composite timber concrete beam. In: Transactions of the VŚB- Technical University of Ostrava, Civil Engineering Series (2012).

[5] A.M.P.G. Dias, S.M.R. Lopes, J.W.G. Van de Kuilen, H.M.P. Cruz, Load-carrying capacity of timber-concrete joints with Dowel-type fasteners. Journal of structural engineering 133 (2007): 720-727.

[6] J. Poštulka, J. Sandanus, Berechnungsverfahren für eine Holz-Beton-Vergunddecke mit Nägeln als vergindungsmittel, Bautechnik 76 (11)(1999): 1026-1030.

[7] ČSN EN 1995-1-1, Eurocode 5 - 2006: Design of timber structures: Part 1-1: General - Common rules and rules for timber structures.

[8] J. Sandanus, Parametric study of the factors affecting the resistance of a composite timber-concrete cross-section, Wood Research 52(3)(2007): 109-114.

[9] A. Lokaj, K. Vavrušová, E. Rykalová, Application of laboratory tests results of dowel joints in cement-splinter boards VELOX into the fully probabilistic methods (SBRA method), Applied Mechanics and Materials 187 (2011): 95-99.

[10]P. Agel, A. Lokaj, Semi-Rigid Joint of Timber-Concrete Composite Beams with Steel Plates and Convex Nails, Wood Research (2014) 59(3): 491-498. 